\title{
The electrical switching characteristics of single copper tetra-cyanoquinodimethane nanowire
}

\author{
K. B. Zheng ${ }^{1}$, H. T. Shen ${ }^{1}$, C. N. Ye ${ }^{2}$, J. L. Li ${ }^{1}$, D. L. Sun ${ }^{1}$ and G. R. Chen ${ }^{1, *}$
}

In this paper, method combined vapor transportation with in-situ chemical reaction is employed to synthesize $\mathrm{Cu}$ (TCNQ) nanowires. The typical diameter of nanowires is $50-500 \mathrm{~nm}$ with high uniformity. The electrical switching characteristics of single nanowire are observed. The ON-OFF resistance ratio for switching reaches $10^{4}$. The investigation reveals a linear relationship between the switching threshold and the spacing between the two electrodes. The temporal response of the switching process is $30 \mathrm{~ns}$ and the switch exhibits good reproducibility. The collapse of the nanowire under the condition of current surge is also discussed. It is believed that the $\mathrm{Cu}(\mathrm{TCNQ})$ nanowire could be promising for applications in nanoelectronics.

Keywords: $\mathrm{Cu}(\mathrm{TCNQ})$; Nanowire; Electrical switching; Charge transfer Complexes

Citation: K. B. Zheng, H. T. Shen, C. N. Ye, J. L. Li, D. L. Sun and G. R. Chen, "The electrical switching characteristics of single copper tetra-cyanoquinodimethane nanowire", Nano-Micro Lett. 1, 23-26 (2009). doi:10.5101/nml. v1i1.p23-26

Metal-TCNQ (7,7,8,8-Tetracyanoquinodimethane) charge transfer complexes have long been considered as organic logical and memory materials due to their electrical switching phenomena induced by the structural phase transition in the mix-stack columns in the form of solitons [1]. The phenomenon and mechanism of the switching effect has been widely discussed in Metal-TCNQ formed with different metals, such as $\operatorname{Ag}(\mathrm{TCNQ}), \mathrm{Cu}(\mathrm{TCNQ}), \mathrm{K}(\mathrm{TCNQ})$, and $\mathrm{Rb}(\mathrm{TCNQ})$ over the past 40 years [2-6]. However, the difficulty in device integration and large switching delay time for traditional bulk and film materials has restricted their application in high-density electronic devices.

Since its recently discovered quasi-one-dimensional nanostructures, $\mathrm{Cu}(\mathrm{TCNQ})$ has attracted renewed attention because of its large surface to volume ratio and size effects which exhibit perfect crystal structure and opens up prospects for high-density nanoelectronics devices [7,8]. Recently, some researches on the switching properties and prototype device fabrication of the $\mathrm{Cu}(\mathrm{TCNQ})$ nanostructures have been reported. Liu [9] and Xiao [10] reported the directed integration of
$\mathrm{Cu}(\mathrm{TCNQ})$ nanowires by a lateral bridging growth method and the observation of a bistable electrical switching; R. Muller [11] investigated the electrical properties of $\mathrm{Cu}(\mathrm{TCNQ})$ nanotubulars in $\mathrm{Au} / \mathrm{CuTCNQ} / \mathrm{Au}$ nanojunction formed by electroplating method and obtained nonvolatile electrical switching with an ON-OFF current ratio of $10^{3}$. Although such researches have significantly enhanced the understanding of the CuTCNQ nanostructure materials, the above-mentioned nanostructures are difficult to reveal the intrinsic switching characteristics of $\mathrm{Cu}(\mathrm{TCNQ})$ nanostructure and not well suited for reproducible device since all these nanostructures were formed by multiple nanounits (nanowire, nanotubular) which were disorderly arranged and loosely packed between the electrodes.

In previous work, we introduced a method combined with physical vapor transportation and in-situ chemical reaction to synthesize single crystalline nanowires of $\mathrm{Ag}(\mathrm{TCNQ}), \mathrm{Cu}$ (TCNQ) and K(TCNQ) [12]. In this paper, single $\mathrm{Cu}(\mathrm{TCNQ})$ nanowire was assembled between the two $\mathrm{Ni} / \mathrm{Au}$ electrodes via photolithography, and the electrical switching of the nanowire

\footnotetext{
1 Department of Materials Science, Fudan University, Shanghai 200433, China

2 Department of Materials Science and Engineering, Soochow University, Suzhou, JiangSu 215006, China

*Corresponding author. Email: kbzheng@163.com
} 
has been measured which exhibited a current ON-OFF ratio of $10^{4}$. Moreover, the temporal process, the reproducibility and the stability of the switching process were discussed. We believe that single $\mathrm{Cu}(\mathrm{TCNQ})$ nanowire could be employed as a switching unit with promising controllability and uniformity, which could avail the logical device application in the future.

a) Nanowires synthesis:

$\mathrm{Cu}(\mathrm{TCNQ})$ nanowires were synthesized by a method that combining physical and chemical vapor deposition techniques. A $10 \mathrm{~nm} \mathrm{Cu}$ film was deposited first on a silicon (111) substrate in a thermal evaporator in vacuum. Then $\mathrm{Cu}$ thin film was placed together with TCNQ powder ( $98 \%$ Aldrich) in a glass tube. After the tube pumped down to $2 \times 10^{-3} \mathrm{~Pa}$, it was sealed and put into a furnace, where the temperature was ramped to $100^{\circ} \mathrm{C}$ and the nanowires would form. The $\mathrm{Cu}$ film was under saturated vapor of TCNQ in this condition. The reaction was expressed as follows:

$$
\mathrm{Cu}^{0}+\mathrm{TCNQ}^{0} \rightarrow \mathrm{Cu}(\mathrm{TCNQ})
$$

The phase structure and chemical state of as-obtained nanowires were identified by a Rigaku X-ray diffractometry with $\mathrm{Cu} \mathrm{K} \alpha 1$ incident radiation and Raman spectrometer with an excitation wavelength of $632.8 \mathrm{~nm}$. A Philips XL30FEG SEM was employed to observe the morphology of the $\mathrm{Cu}(\mathrm{TCNQ})$ nanowires.

b) Measurement on the electrical switching of the nanowire:

In order to measure the $\mathrm{I}-\mathrm{V}$ properties of individual $\mathrm{Cu}$ (TCNQ) nanowire, as-obtained nanowires were separated from the substrate by ultrasonication in alcohol. The suspension was then deposited onto a silicon chip capped with a layer of 200-500 $\mathrm{nm} \mathrm{SiO}_{2}$. Photolithography was employed to form a
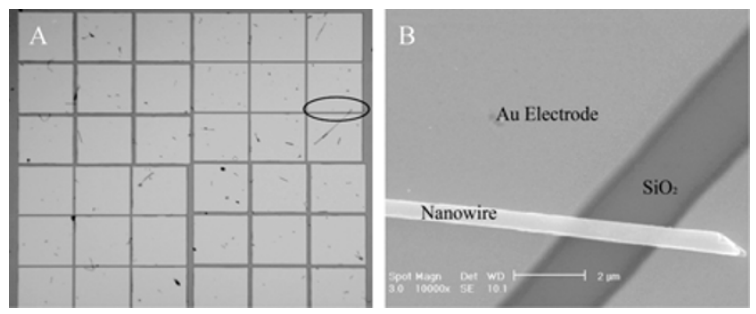

FIG. 1. (A) Optical image of Ni/Au pads array, (B) SEM image showing one nanowire in contact with two pads.
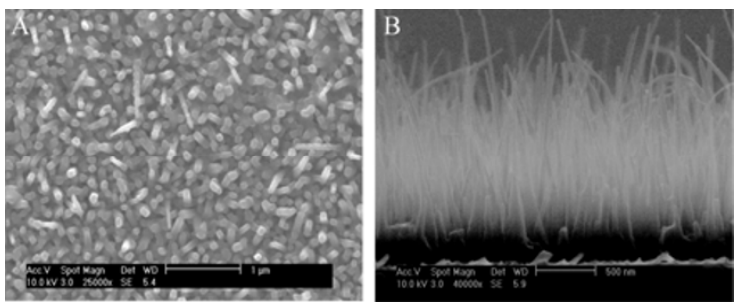

FIG. 2. (A) Top view (B) cross-sectional SEM of $\mathrm{Cu}(\mathrm{TCNQ})$ nanowires synthesized on the $\mathrm{Si}$ substrate at $100^{\circ} \mathrm{C}$ with a reaction time of $1 \mathrm{~h}$ square electrodes array which consisted of $10 \mathrm{~nm}$ of $\mathrm{Ni}$ and 100 $\mathrm{nm}$ of $\mathrm{Au}$, as can be seen in Fig. 1A. Individual nanowire with good contacts on both ends were then located using SEM as shown in Fig. 1B. During the measurement the load resistor placed in series with the sample should be carefully picked in order to avoid the collapse of nanowire resulting from the heating effect of the current which will be discussed below.

SEM image (Fig. 2) shows vertically grown nanowires on the Si substrate with a typical diameter around 50-500 $\mathrm{nm}$. The growth of $\mathrm{Cu}(\mathrm{TCNQ})$ nanowires conformed to a Vapor-LiquidSolid mechanism [13]. TCNQ vapor diffused into liquefied droplets of $\mathrm{Cu}$ and reacted with it to form co-melting droplets of $\mathrm{Cu}$ and $\mathrm{Cu}(\mathrm{TCNQ})$ as illustrated in Scheme 1A. The excess $\mathrm{Cu}(\mathrm{TCNQ})$ with high surface activity precipitated gradually and formed nuclei as illustrated in Scheme 1B. Then the dissolved $\mathrm{Cu}(\mathrm{TCNQ})$ continued to precipitate and stacked in the existing interface on the droplets to grow in the preferential direction as illustrated in Scheme 1C.

Figure 3A showed Raman spectrum of the as-obtained nanowires and neutral TCNQ. The band at $2229 \mathrm{~cm}^{-1}, 1205$ $\mathrm{cm}^{-1}$ and $1607 \mathrm{~cm}^{-1}$ was assigned to the $\mathrm{C} \equiv \mathrm{N}$ stretching, $\mathrm{C}=\mathrm{CH}$ bending mode and the $\mathrm{C}=\mathrm{C}$ ring stretching mode of $\mathrm{Cu}(\mathrm{TCNQ})$ molecules, respectively. Compared with the Raman spectrum of neutral TCNQ, the $\mathrm{C}-\mathrm{CN}$ stretching mode in the as-obtained nanowires shifted from 1455 to $1374 \mathrm{~cm}^{-1}$, indicating a charge transfer between $\mathrm{Cu}$ and TCNQ [14,15]. Figure 3B showed XRD powder pattern of the nanowires. The intense features in the low-angle region identified that the as-prepared nanowires belonged to phase I [16].

To confirm the electrical switching of $\mathrm{Cu}(\mathrm{TCNQ})$

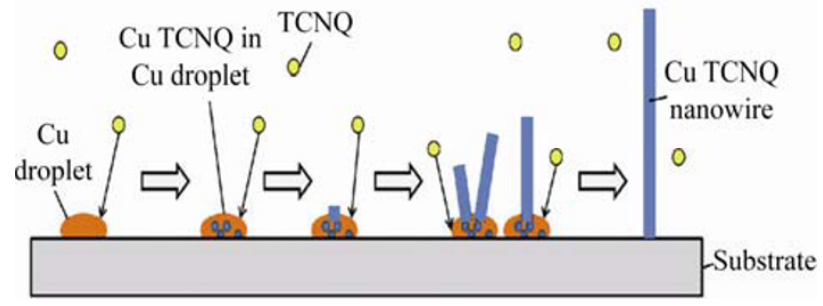

Scheme 1. Schematic illustration for the growth of aligned $\mathrm{Cu}(\mathrm{TCNQ})$ nanowires.
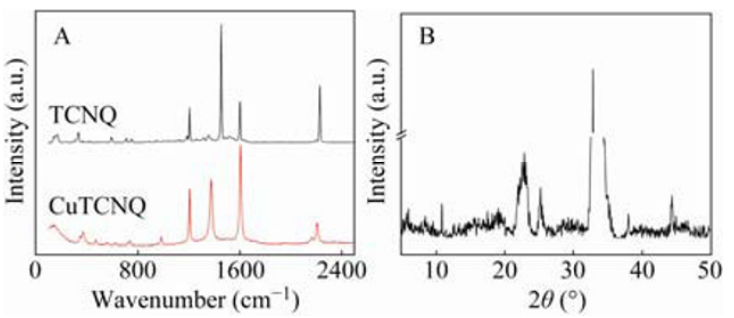

FIG. 3. (A) Raman, (B) XRD pattern of $\mathrm{Cu}(\mathrm{TCNQ})$ nanowires. 
nanowires, we fabricated prototype device to measure the current-voltage (I-V) characteristics of individual $\mathrm{Cu}(\mathrm{TCNQ})$ nanowire (as shown in Fig. 4A). The sample for measurement here was $400 \mathrm{~nm}$ in diameter and the spacing between the two electrodes was $2.1 \mu \mathrm{m}$ (Fig. 1B). When the voltage applied to the device was increased to the threshold of $34 \mathrm{~V}$, the current rapidly increased, indicating the sample transfer from a high-resistance to a low-resistance state. After the voltage was swept down to $0 \mathrm{~V}$, the sample turned back to high-resistance. The nanowire resistance in the high-resistance state and low-resistance state was approximately $10 \mathrm{G} \Omega$ and $2.83 \mathrm{M} \Omega$, respectively. The actual ON-OFF resistance ratio for switching reaches in 4 orders as can be seen in the logarithmic plot for I-V in Fig. 4A.

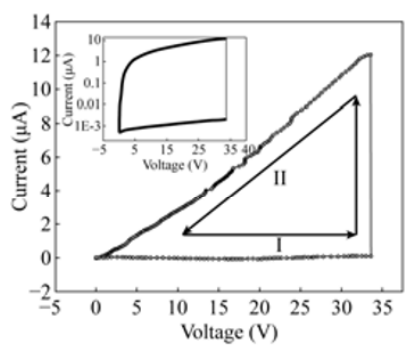

A

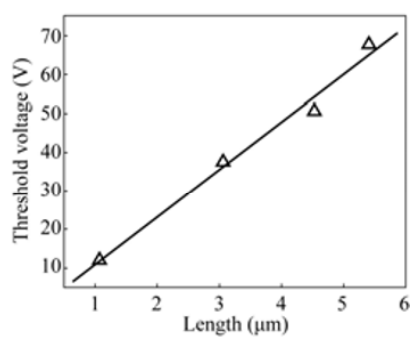

B
FIG. 4. (A) I-V characteristics of individual $\mathrm{Cu}(\mathrm{TCNQ})$ nanowire, and the arrow demonstrated the sequence of applying the voltage. State I and II indicated the electrical 'OFF' and 'ON' states, respectively. (B) The spacing between the two electrodes versus the switching threshold.

No previous researches on the single $\mathrm{Cu}(\mathrm{TCNQ})$ nanoribbon with $20 \mu \mathrm{m}$ in length showed switching effect during the electrical measurement [9]. This can be explained by the the field driving solitions transportation model for tranditional MTCNQ crystal [2] which also has been proved in our experiment for nanoscaled structures. After we carefully selected the spacing between the two electrodes during the I-V measurement, the proportional relationship between the threshold voltage of $\mathrm{Cu}(\mathrm{TCNQ})$ nanowire and the length of the nanowire between the electrodes has been revealed, indicating the local field dependence of the phase transition. Therefore, the free motion of the minority of charged defects solitons is hindered by the interstack repulsion at low fields. When the electric field is raised to a critical threshold, a positive feedback process occurred in which the field-induced motion of defects leads to an accelerated loosening of the interstack interaction and consequently ends in a sudden break of the long-range BOW state [2]. That is the switching effect would not happen until the nanowire reach its threshold of local electric field, which was $12.1 \mathrm{~V} / \mu \mathrm{m}$ for $\mathrm{Cu}(\mathrm{TCNQ})$ nanowire as illustrated in Fig. 4B.
Figure 5A demonstrates the temporal response of the switching process after a positive pulse voltage $\mathrm{V}_{0}$, with $75 \mathrm{~V}$ in amplitude and $150 \mathrm{~ns}$ in width was applied to the nanowire. The length of the nanowire between the two electrodes here was $2.4 \mu \mathrm{m}$. Once the voltage on the sample $\mathrm{V}_{1}$ reached the switching threshold voltage of $26 \mathrm{~V}$ it transited from a highresistance to a low-resistance state, and afterwards $V_{1}$ fell down rapidly. The fall time of approximately $30 \mathrm{~ns}$ was the temporal response of the switching process. Compared with traditional M-TCNQ bulk or thin film materials average charge transfer process in molecules, the temporal response of $\mathrm{Cu}(\mathrm{TCNQ})$ nanowires appeared to be faster. In particular, the previous temporal response measured on Ag(TCNQ) [17] and K(TCNQ) [6] thin film exhibits a slower delay time $T_{d}$ in $\mu$ s order when the voltage on sample rises from $0 \mathrm{~V}$ to its switching threshold as illustrated in Fig. 5B, whereas such effect could be neglected in $\mathrm{Cu}(\mathrm{TCNQ})$ nanowire. The reason for this was that the switching we observed resulted from the charge transfer in huge amount of molecules instead of one single molecule [2]. The nonlinear increasing of $\mathrm{V}_{1}$ shown in Fig. 5B indicates an energy absorbing process occurs during the break of the long-range

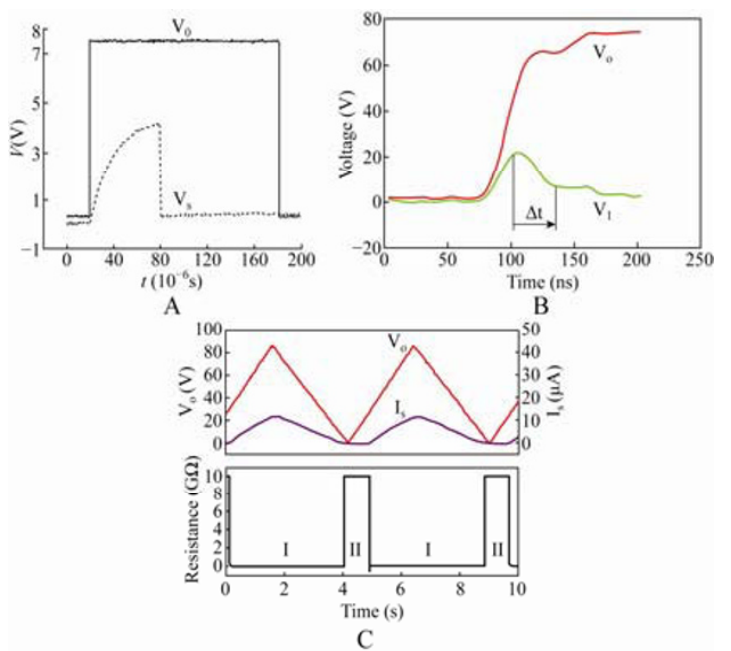

FIG. 5. (A) The temporal measurement describing the break of the nanowire, (B) $\mathrm{I}-\mathrm{V}$ characteristics of $\mathrm{M}(\mathrm{TCNQ})$ thin films and (C) The reproducible measurement of the nanowire.

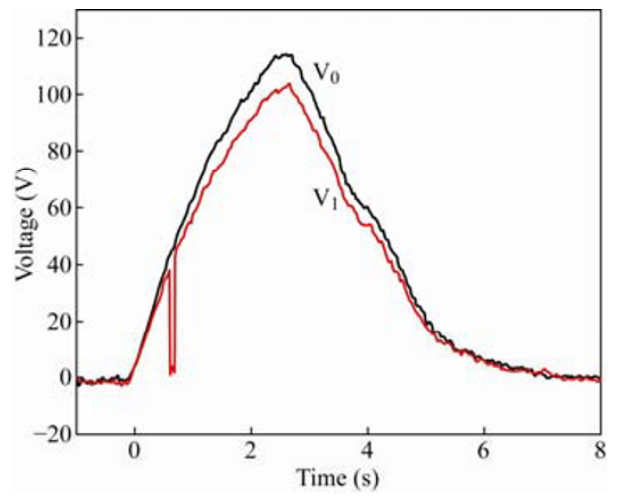

FIG. 6. The temporal measurement describing the collapse of the nanowire. http://www.nmletters.org 
BOW state. Owing to the size effect of every individual nanowire, the required energy for the macroscopically current switching is much lower and thus can be supplied within an ultrafast time.

The switching process also exhibited good reproducibility as shown in Fig. 5C. When the applied pulse voltage was substituted with a periodical triangle signal, a periodical change in current could be observed that almost no current flew through the device in high-resistance state (I) while a current in $\mu \mathrm{A}$ order could be measured in low-resistance state (II). The resistance change of the switching device in two states was also plotted in Fig. 5C.

It should also be mentioned that, in order to avoid the collapse of nanowire, a proper load resistor should be placed in series with the sample. Figure 6 illustrates the temporal measurement showing the collapse of the nanowire during the electrical measurement. The spacing between the two electrodes here was $3 \mu \mathrm{m}$. The load resistor used here was $10 \mathrm{~K} \Omega$, much lower than the resistor of $1 \mathrm{M} \Omega \sim 10 \mathrm{M} \Omega$ employed in normal measurement. A triangle scanning voltage was applied to the sample. $\mathrm{V}_{0}$ was the output voltage of the power source, and $\mathrm{V}_{1}$ was the voltage on the sample. As shown in the inset, when the voltage applied to the sample was below $38 \mathrm{~V}, \mathrm{~V}_{1}$ was almost equal to $\mathrm{V}_{0}$ indicating the nanowire was in high- resistance state. The switching occurred at the threshold of $38 \mathrm{~V}$ with a sharp decline of $\mathrm{V}_{1}$. Consequently, however, the surge of the current would rapidly heat the nanowire to callapse and $\mathrm{V}_{1}$ suddenly increased at the voltage of $41 \mathrm{~V}$.

The future application for the as-prepared structure is diversified in terms of these properties. For instance, due to the quick switching response, the device can serve as over-voltage protector when connected in parallel with other device. When a large voltage occurs, the switching device will swiftly transfer to low-resistance state and 'short-circuit' the system preventing other device from break.

$\mathrm{Cu}(\mathrm{TCNQ})$ nanowires were successfully synthesized by method combined vapor transportation with in-situ chemical reaction. The electrical switching effect with high $\mathrm{ON}-\mathrm{OFF}$ ratio of approximately $10^{4}$ was observed in individual $\mathrm{Cu}$ (TCNQ) nanowire. The measurement demonstrated that the threshold voltage of the switching was proportional to the length of the nanowire between the electrodes. The electrical switching of the nanowire exhibited fast temporal response of $30 \mathrm{~ns}$ and fine reproducibility. These unique properties indicate their promising applications in nanoelectronics.
The authors acknowledge financial support from Shanghai Science and Technology Development Fund (No. 0752nm016) and Shanghai Leading Academic Development Project (No. B113).

\section{Received 01 October 2009; accepted 13 October 2009; published} online 15 October 2009

\section{References}

1. R. S. Potember, T. O. Poehler and D. O. Cowan, Appl. Phys. Lett. 34, 405 (1979). doi:10.1063/1.90814

2. Y. Iwasa, T. Koda, Y. Tokura, S. Koshihara, N. Iwasawa and G. Saito, Appl. Phys. Lett. 55, 2111 (1989).

3. R. Kumai, Y. Okimoto and Y. Tokura, Science 284, 1645 (1999). doi:10.1126/science.284.5420.1645

4. N. Watanabe, Y. Iwasa and T. Koda, Phys. Rev. B 44, 11111 (1991). doi:10.1103/PhysRevB.44.11111

5. Z. Y. Hua and G. R. Chen, Vaccum 43, 1019 (1992).

6. X. L. Mo, G. R. Chen, Q. J. Cai, Z.Y. Fan, H. H. Xu, Y. Yao, J. Yang, H. H. Gu and Z. Y. Hua, Thin solid films, 436, 259 (2003). doi:10.1016/S0040-6090(03)00593-5

7. P. O. Anthony, F. Nigel, N. Ayman and M. B. Alan, J. Am. Chem. Soc. 129, 2066 (2007). doi:10.1021/ja066874o

8. Y. L. Liu, Z. Y. Ji, Q. X. Tang, L. Jiang, H. X. Li, M. He, W. P. Hu, D. Q. Zhang, L.Jiang, W. K. Wang, C. Wang, Y. Q. Liu and D. B. Zhu, Adv. Mater. 17, 2953 (2005). doi:10.1002/adma.200500809

9. Y. L. Liu, H. W. Li, D. Y. Tu, Z. Y. Ji, C. S. Wang, Q. X. Tang, M. Liu, W. P. Hu, Y. Q. Liu and D. B. Zhu, J. Am. Chem. Soc. 128, 12917 (2006). doi:10.1021/ja0636183

10. K. Xiao, I. N. Ivanov, A. A. Puretzky, Z. Liu and D. B. Geohegan, Adv. Mater. 18, 2184 (2006). doi:10.1002/ adma.200600621

11. R. Muller, J. Genoe and P. Heremans, Appl. Phys. Lett. 88, 242105 (2006). doi:10.1063/1.2213971

12. G. R. Chen and X. L. Mo, Chinese patent (State intellectual properties office of P.R.C) , 02151236.1 (2002)

13. C. N. Ye, G. Y. Cao, F. Fang, H. H. Xu, X. Y. Xing, D. L. Sun and G. R. Chen, Micron 36, 461 (2005).

14. P. G. Gucciardi, S. Trusso, C. Vasi, Patane and M. Allegrin, Phys. Chem. Chem. Phys. 4, 2747 (2002).

15. R. S. Potember, T. O. Poehler and R. C. Benson, Appl. Phys. Lett. 41, 548 (1982). doi:10.1063/1.93591

16. R. A. Heinta, H. Zhao, X. Wuyang, G. Grandinetti, J. Cowen and K. R. Dunbar, Inorg. Chem. 38, 144 (1999).

17. X. G. Wan, J. Li, D. Y. Chen, Y. M. Jiang and Z. Y. Hua, Phys. Stat. Sol. (a) 181, R13 (2000). 